\title{
Night-to-night changes in the characteristics of gravity waves at stratospheric and lower-mesospheric heights
}

\author{
A. J. McDonald, L. Thomas, D. P. Wareing \\ Department of Physics, The University of Wales, Aberystwyth, Ceredigion, SY23 3BZ, UK
}

Received: 24 February 1997; Revised: 2 August 1997; Accepted: 25 August 1997

\begin{abstract}
Observations made with the co-located Rayleigh lidar and MST radar systems at Aberystwyth $\left(52.4^{\circ} \mathrm{N}, 4.1^{\circ} \mathrm{W}\right)$ in Wales and radiosondes from Valentia $\left(51.9^{\circ} \mathrm{N}, 10.2^{\circ} \mathrm{W}\right)$ in Eire are used to investigate the changes in the vertical propagation of gravity waves during periods of 4 days in June 1995 and February 1993. In each month, the lidar observations show that the wave activity in the upper stratosphere and lower mesosphere changes between two pairs of days. The radar and radiosonde measurements indicate that mountain waves make no contribution to the changes in intensity. Instead, the changes seem to arise largely from the presence or absence of long-period waves with vertical wavelengths near 8 and $10 \mathrm{~km}$ in June and February, respectively. The influence of such waves on the vertical wavenumber spectra is examined and related to the evidence for convective instabilities provided by the temperature profiles.
\end{abstract}

Key words Rayleigh lidar · MST radar systems · Radiosondes · Gravity waves

\section{Introduction}

Early studies recognised that the perturbations of wind, temperature and other parameters associated with an upward-propagating gravity wave will grow with increasing height due to decreasing atmospheric density, and at some level are likely to induce convective or shear instability. At these levels, the amplitude growth would cease because of the extraction of wave energy to generate turbulence (Hodges, 1967, 1969). Loss of wave energy and momentum to the mean flow also occurs at a

Correspondence to: Prof. L. Thomas

Fax: + 01970622826 "critical layer" where the phase velocity of the wave matches that of the background wind (Bretherton, 1966; Booker and Bretherton, 1967). The upward transport and deposition of momentum and energy from lower heights provides a major part of the dynamical coupling between different parts of the atmosphere, and thereby determines the general circulation and structure of the middle atmosphere (Houghton, 1978; Lindzen, 1981; Holton, 1983).

A variety of techniques have been used to observe the fluctuations of temperature and wind which are characteristic of internal gravity waves. VanZandt (1982) noted that the power spectra expressed as functions of frequency, horizontal wavenumber and vertical wavenumber at a number of locations, during different seasons and meteorological conditions, show very similar forms. Explanations of the characteristic shape of the vertical wavenumber power spectra in terms of saturation caused by linear instabilities were advanced by Dewan and Good (1986) and Smith et al. (1987). Subsequent descriptions of the observed spectra in terms of the mechanisms of Doppler spreading and dissipation due to scale-dependent diffusion were presented by Hines (1991) and Weinstock (1990), respectively.

Of the techniques capable of measuring gravity-wave parameters at middle-atmospheric heights, only the Rayleigh-lidar approach has provided successive profiles extending over heights within the range $30-75 \mathrm{~km}$ over several hours, even if confined to the hours of darkness. Such measurements have shown changes in activity from hour to hour, day to day and with season (Shibata et al., 1988; Marsh et al., 1991; Mitchell et al., 1991; Wilson et al., 1991a,b; Whiteway and Carswell, 1994,1995). Whiteway and Carswell (1995) observed that the height variation of the mean potential energy per unit mass for the months of January, March, June and September at Toronto $\left(44^{\circ} \mathrm{N}, 80^{\circ} \mathrm{W}\right)$, Canada, showed a growth rate less than that necessary for the conservative growth of waves. In contrast, Mitchell et al. (1991) at Aberystwyth $\left(52.4^{\circ} \mathrm{N}, 4.1^{\circ} \mathrm{W}\right)$, Wales, showed that this effect was pronounced in winter but not in summer months. The 
results of Marsh et al. (1991) at the same site also showed that the characteristic vertical wavenumber spectrum, with a slope of -3 at large wavenumbers predicted by theory, is observed in winter but not in other seasons. One aspect of the overall measurements relevant to considerations of wave saturation (Smith et al., 1987) is the change with height of the wave energy at large vertical wavenumbers. The lidar measurements of Whiteway and Carswell $(1994,1995)$ at both Toronto and Eureka $\left(80^{\circ} \mathrm{N}, 86^{\circ} \mathrm{W}\right)$ show no change between the lower and middle stratosphere and lower mesosphere, in keeping with the results for the troposphere and lower statosphere derived by Allen and Vincent (1995) from radiosonde data for low and middle latitudes in the southern hemisphere. In contrast, the lidar measurements of Wilson et al. (1991a, b), Beatty et al. (1992) and Senft et al. (1993), all at middle latitudes in the northern hemisphere, show increases in power spectral density between the stratosphere and mesosphere over the full spectral range. The results of Whiteway and Carswell (1995) and Marsh et al. (1991) also indicate very marked changes in spectra from day to day and even within a few hours.

The present study is based on the use of Rayleighlidar measurements at Aberystwyth to investigate the characteristics of gravity waves in the $35-65-\mathrm{km}$ height range, supplemented by co-located VHF radar velocity measurements for changes up to about $20 \mathrm{~km}$ and radiosonde wind measurements from Valentia $\left(51.9^{\circ} \mathrm{N}\right.$, $\left.10.2^{\circ} \mathrm{W}\right)$, Eire, for heights between 20 and $27 \mathrm{~km}$. Radiosonde stations nearer Aberystwyth provided no measurements above $20 \mathrm{~km}$. Data sets for four nights in the months of June 1995 and February 1993 have shown marked changes in wave activity in the upper stratosphere and lower mesosphere between adjacent or closely spaced nights, the changes originating largely in waves of vertical wavelengths $8 \mathrm{~km}$ or greater.

\section{Experimental systems}

The Rayleigh lidar system used has been described by Thomas et al. (1983), except that in the mean time the Neodymium-Yag laser has been upgraded to provide a maximum pulse repetition frequency of $15 \mathrm{~Hz}$ and a mean power of $7.5 \mathrm{~W}$ at $532 \mathrm{~nm}$. The receiver makes use of a 0.9 m-diameter mirror in a Newtonian-type configuration which provides a 1-mrad field of view, slightly larger than that of the transmitted beam. The detector was a modified EMI 9902 photomultiplier operated in the photon-counting mode, the output pulses being fed to an Ortec discriminator and multichannel scaler which provide a range resolution of $300 \mathrm{~m}$. The initial photon integration extends over a total of 1800 laser pulses, corresponding to a sampling time of $2 \mathrm{~min}$, but under normal conditions ten such samples are summed before analysis, thereby producing a backscatter profile about every $20 \mathrm{~min}$. Observations of Rayleigh backscatter provide measurements of relative atmospheric density in regions free of aerosol concentrations, after corrections for Rayleigh attenuation and ozone absorption have been applied to the returned signal, and these measurements have also been used to derive profiles of atmospheric temperature as described by Jenkins et al. (1987). The need to avoid returns from aerosols restricted the observations to heights above $35 \mathrm{~km}$.

Supporting velocity measurements at heights below about $20 \mathrm{~km}$ have been provided by the Natural Environment Research Council MST radar facility. This radar operates at $46.5 \mathrm{MHz}$, has a peak power of $160 \mathrm{~kW}$, and a one-way beamwidth of $3^{\circ}$ produced by a $110 \times 110$-m antenna array of 400 four-element Yagis. The measurements used in the present study employed a vertical and two $6^{\circ}$ off-vertical beams in orthogonal planes, to provide horizontal and vertical velocities with a height resolution of $300 \mathrm{~m}$ and a sampling time of 12 $\min$.

\section{Measurements and analysis of results}

The mean temperature profiles for the four summer nights, 26-29 June 1995, and four winter nights, 13, 19, 22 and 24 February 1993, of interest are shown in parts $\mathrm{a}$ and $\mathrm{b}$ of Fig. 1, respectively. Also shown for the two groups of nights are the June and February mean temperatures for $50^{\circ} \mathrm{N}$, from the CIRA-1986 model. Large-amplitude wave-like perturbations are clearly seen in the profiles for the February nights. In addition, it will be shown that the features observed below $45 \mathrm{~km}$ on the 27 and 28 June represent significant wave-like perturbations. It is also seen that the temperatures on the four February nights are substantially larger than the model values at all heights up to the stratopause and for certain ranges at greater heights. The differences are associated with a minor stratospheric warming in
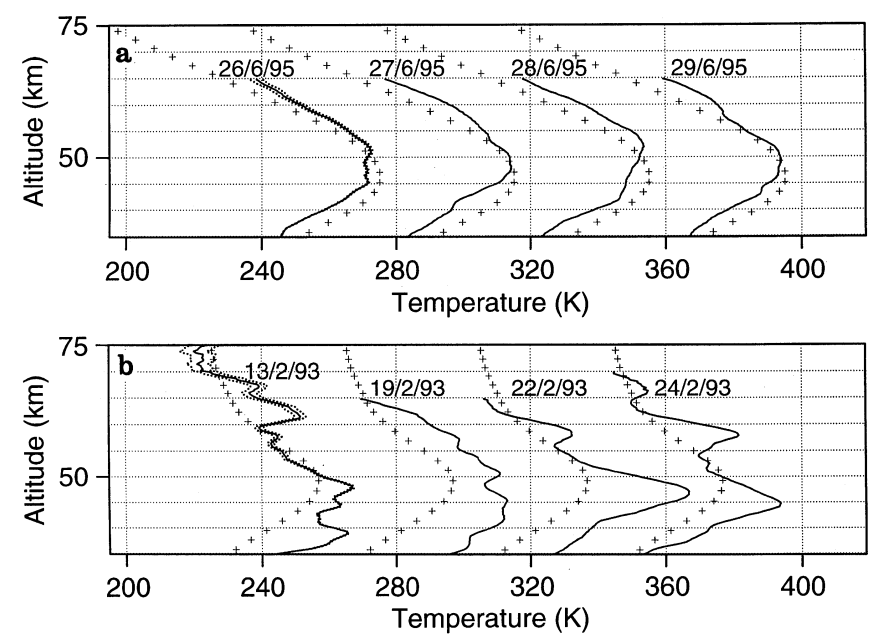

Fig. 1a, b. Mean night-time temperature profiles, represented by full lines, derived from Rayleigh lidar measurements, for a nights of 26-29 June 1995 and b nights of 13, 19, 22, and 24 February 1993. The successive profiles in each group are offset by $40 \mathrm{~K}$. The climatological mean temperatures for the 2 months taken from the CIRA-1986 model at $50^{\circ} \mathrm{N}$, represented by crosses, are shown for comparison, and also the estimated uncertainties of the mean for the first night of each group 
February (Naujokat et al., 1993). This warming started at the end of January and finished before the end of February, a relatively quiet period at the end of February being observed. For the June nights, the observed temperatures are smaller than the CIRA-1986 values below the stratopause and larger than the model values at greater heights. However, the magnitudes of the differences between the observations and the CIRA1986 values are generally much smaller in June than February. In addition, the February mean temperature profiles are considerably more variable than those in June.

The mean temperature profiles in Fig. $1 \mathrm{~b}$ display height regions of marked lapse rates during the winter nights, especially those of 22 and 24 February. The individual 20-min profiles for these two nights are shown in parts a and b of Fig. 2, respectively. In each case, the dotted lines correspond to the dry adiabatic lapse rate. Certain of the profiles for 22 February show temperature gradients approaching the dry adiabatic rate within the height ranges $48-53 \mathrm{~km}$ and $59-62 \mathrm{~km}$. For 24 February, the lapse rate approaches the dry adiabatic value within the height range 58$62 \mathrm{~km}$ throughout the observational period, and there are some indications of this condition also existing near $50 \mathrm{~km}$ in some profiles. For the two earlier nights, the individual temperature profiles show evidence of dry adiabatic lapse rates chiefly above $65 \mathrm{~km}$ on 13 February and above $60 \mathrm{~km}$ on 19 February, and over very limited height ranges between 45 and $60 \mathrm{~km}$. It seems likely that with a height resolution better than $300 \mathrm{~m}$, other regions of dry adiabatic lapse rates might be identified (Sica and Thorsley, 1996). However, the present results suggest that the primary effects of convective instabilities occur at heights above $50 \mathrm{~km}$.
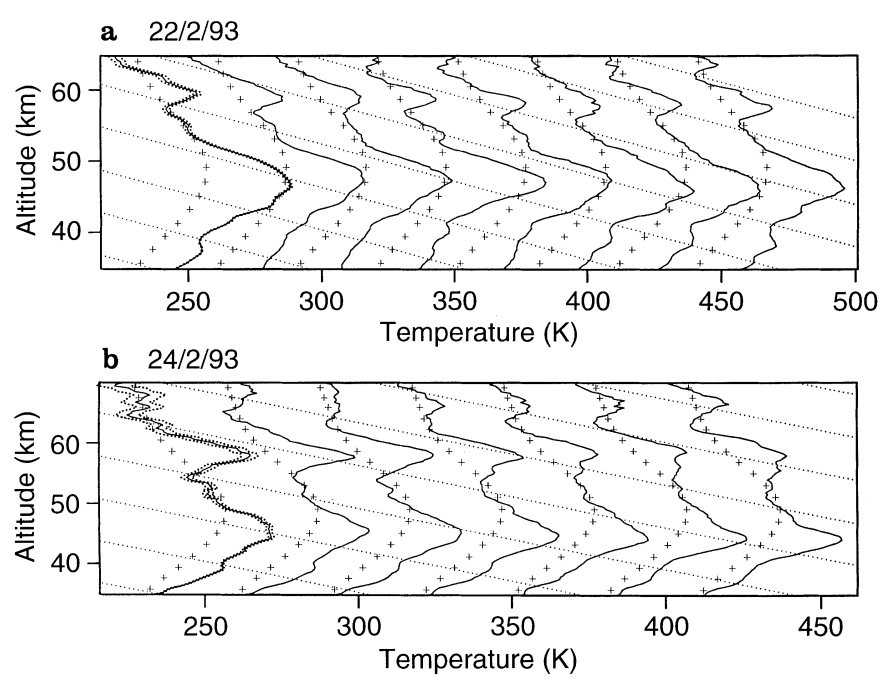

Fig. 2a, b. The individual temperature profiles derived from 20-min observations on the nights of a 22 February 1993 and b 24 February 1993, successive profiles being offset by $40 \mathrm{~K}$. The estimated uncertainties for the first profile for each night are shown. The dotted lines have slopes corresponding to the dry adiabatic lapse rate
An examination of the individual 20-min temperature profiles for the four nights of June 1995 show no evidence of lapse rates approaching the dry adiabatic lapse rate below $50 \mathrm{~km}$. The results for heights above $55 \mathrm{~km}$ show very small height ranges in which the temperature gradients do approach the dry adiabatic value, but there are no clear night-to-night differences.

To illustrate the perturbations due to gravity waves more clearly, profiles of the density fluctuations at 20min intervals are shown for the four nights in June in Fig. 3. The individual profiles for each night have been derived by removing the corresponding cubic-spline approximation to the night-time mean profile from each 20-min profile and expressing the differences as fractions of the mean value. Each fractional density perturbation is then submitted to a high-pass fourth-order Butterworth filter to remove motions with vertical wavelengths greater than $15 \mathrm{~km}$. The sequence of percentage density perturbation profiles for each June night (Fig. 3) suggests the superposition of several waves, but those for 27 and 28 June (Fig. 3b, c) show particularly clear evidence of quasi-monochromatic features with vertical
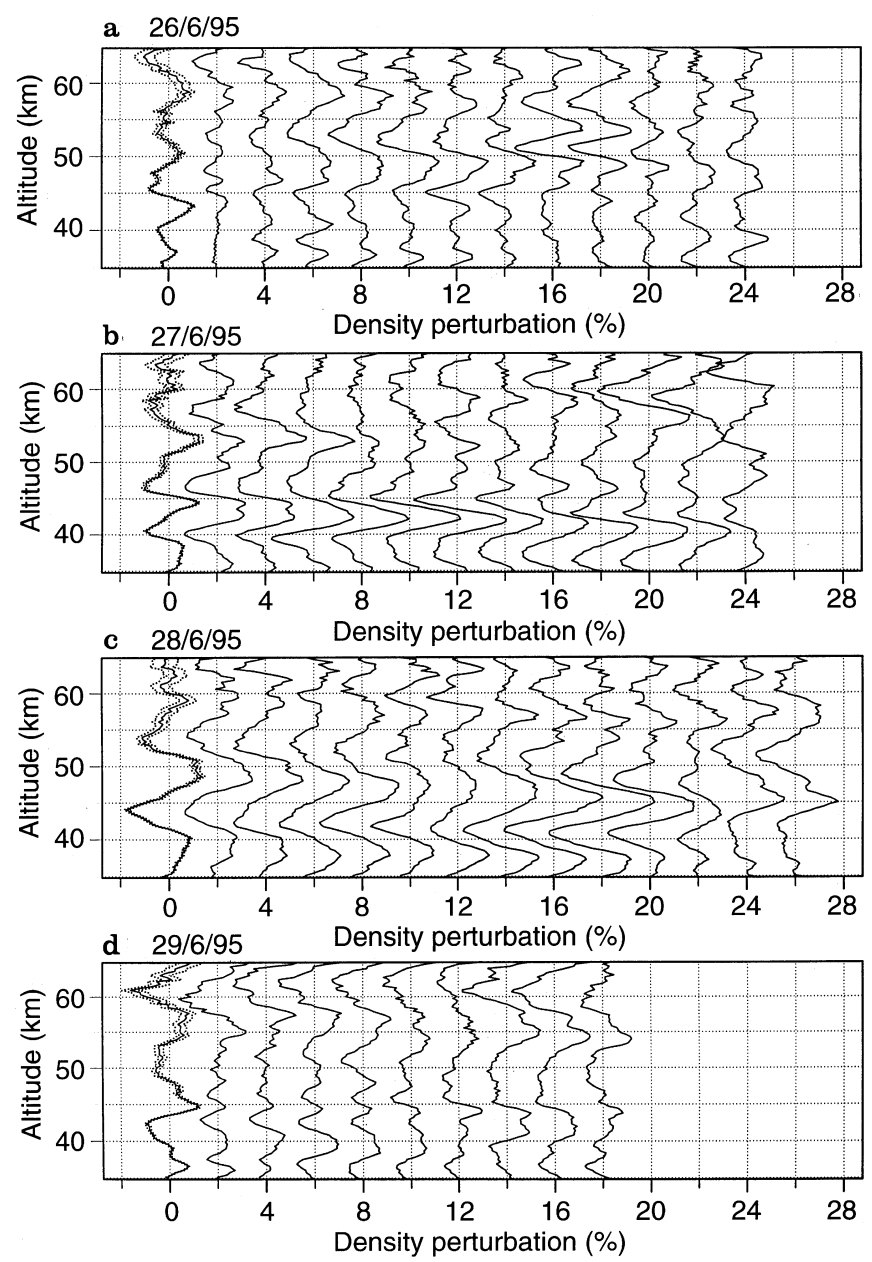

Fig. 3a-d. Profiles of percentage density fluctuations derived from 20min observations on the nights of a 26, b 27, c 28 and $\mathbf{d} 29$ June 1995 , successive profile values being offset by $2 \%$ density perturbation. The estimated uncertainities for the first profile for each night are shown 
wavelengths near $8 \mathrm{~km}$ below about $50 \mathrm{~km}$, and downward phase progression with velocities near $0.3 \mathrm{~m} \mathrm{~s}^{-1}$. No such clear features are apparent in the results for 26 and 29 June (Fig. 3a, d) except above $45 \mathrm{~km}$ for the centre of the period on the 26 June. The vertical wavelengths and downward phase velocities for 27 and 28 June correspond to apparent periods of 6.4 and $9 \mathrm{~h}$, respectively.

The data for the four February nights have been analysed in similar fashion, the individual profiles of percentage density perturbations for each night being displayed in Fig. 4. These again suggest the superposition of several waves, but those for 22 and 24 February are dominated by large quasi-monochromatic waves of vertical wavelengths near 10 and $12 \mathrm{~km}$, respectively. The minima observed at $45-50 \mathrm{~km}$ on 22 February (Fig. 4c) and near $45 \mathrm{~km}$ on 24 February (Fig. 4d) both indicate downward phase progression with phase velocities of about $0.2 \mathrm{~m} \mathrm{~s}^{-1}$. The vertical wavelengths and downward velocities imply apparent periods of 14 and $17 \mathrm{~h}$, respectively. Since the apparent period observed on 24 February is greater than the inertial period at
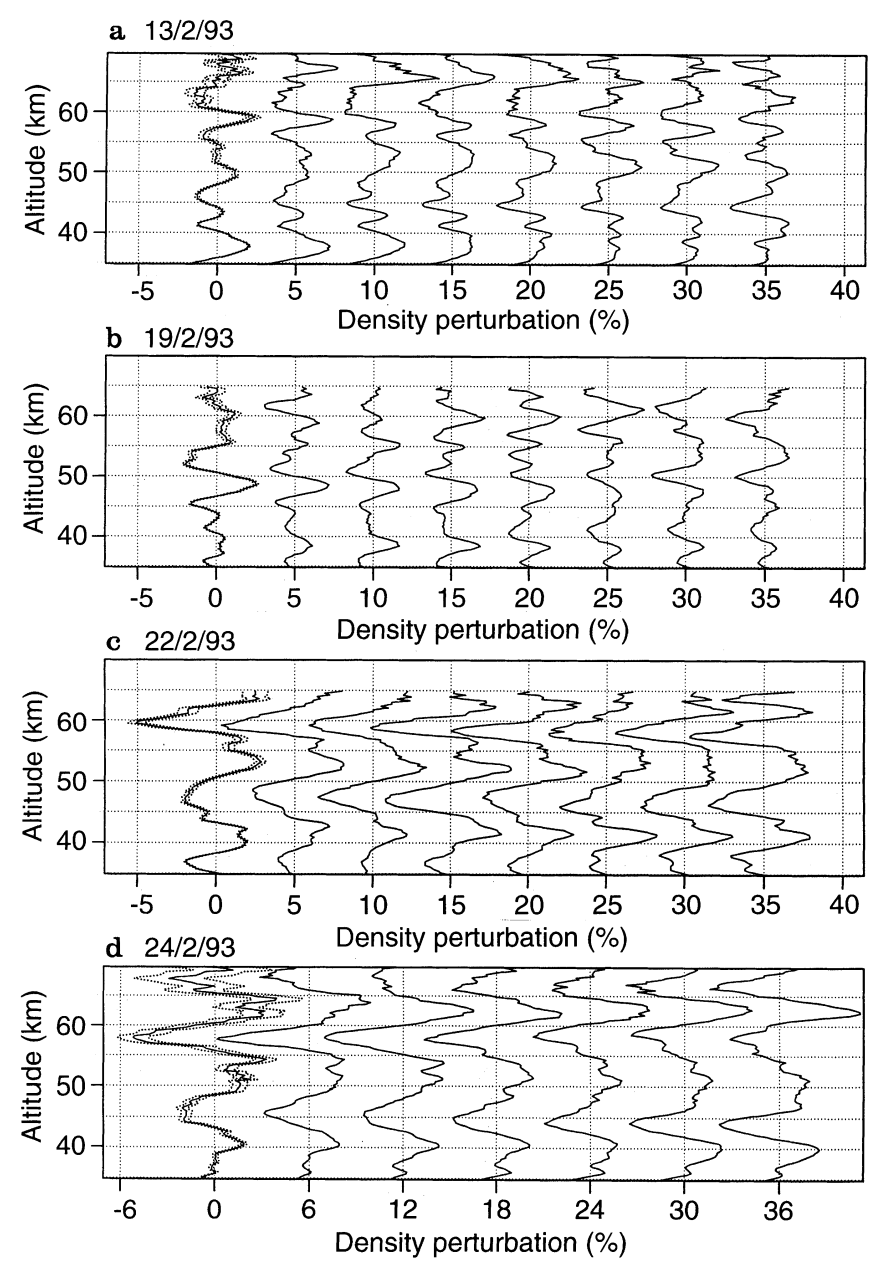

Fig. 4a-d. Profiles of percentage density fluctuations derived from 20min observations on the nights of a 13, b 19, c 22 and d 24 February 1993 , successive profile values being offset by $4 \%$ density perturbation for the first three nights and $6 \%$ for the fourth night. The estimated uncertainities for the first profile for each night are shown
Aberystwyth $(\approx 15.1 \mathrm{~h})$, this wave must be propagating in the opposite direction to the background wind for the correct sense of Doppler shifting to be observed.

Parts a, b, c and d of Fig. 5 show profiles of the mean potential energy per unit mass, $E_{p}$ for each night derived from the individual profiles of fractional density perturbations:

$\overline{E_{p}(z)}=\frac{1}{2}\left(\frac{g}{N(z)}\right)^{2}\left(\frac{\rho \prime(z)}{\overline{\rho(z)}}\right)^{2}$,

where $N(z)$ is the Brunt-Väisälä frequency, $g$ is the acceleration due to gravity and $\rho^{\prime}(z) / \overline{\rho(z)}$ is the fractional density perturbation. The appropriate values of the Brunt-Väisälä frequency are derived from the average temperature profile for each night, the temperature gradient being calculated from the average profile
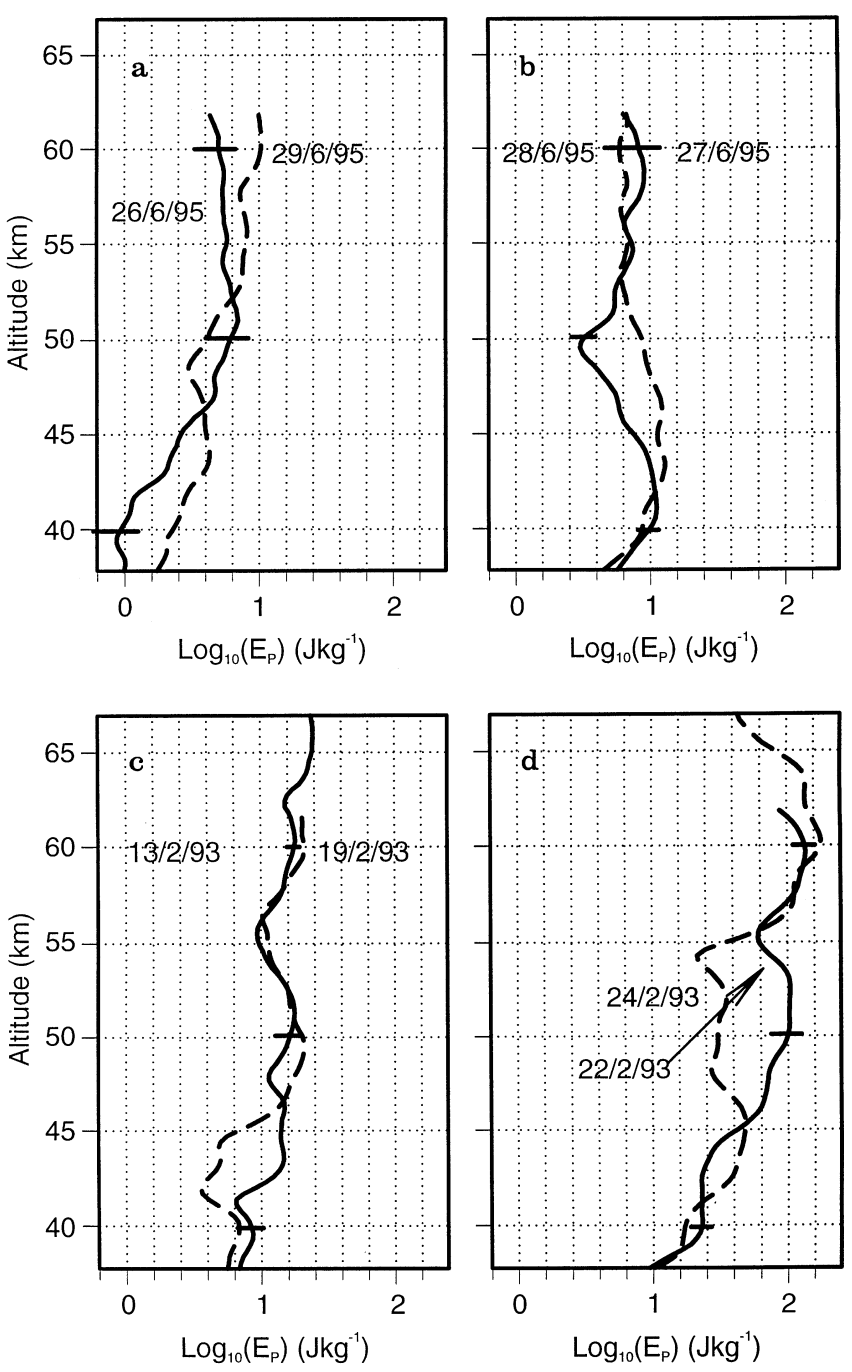

Fig. 5a-d. Profiles of the mean potential energy per unit mass derived from measurements made on the nights of a 26 and 29 June 1995, b 27 and 28 June 1995, c 13 and 19 February 1993 and d 22 and 24 February 1993. The uncertainities in the estimated energies are shown for the full-line profiles by heavy bars at heights of 40, 50 and $60 \mathrm{~km}$ which correspond to one standard deviation 
using a least-squares straight-line fit taken over $1.5-\mathrm{km}$ height intervals.

The profile of potential energy per unit mass for the quiet night on 26 June (Fig. 5a) displays an increase by a factor of 6 between 35 and $50 \mathrm{~km}$, above which it is almost constant. This growth up to $50 \mathrm{~km}$ is about $40 \%$ smaller than that expected if the potential energy per unit mass was conserved, given by $e^{z / H}$, where $H$ is the density scale height, which is typically $6-7 \mathrm{~km}$ in the height range of interest. The profile for the second quiet night on 29 June (Fig. 5a) shows an increase by a factor of about 4 between 35 and $52.5 \mathrm{~km}$, this being smaller by a factor of 3.8 than that expected if the potential energy per unit mass was conserved, and again an almost constant value at greater heights. The profiles for the two active nights, 27 and 28 June (Fig. 5b), show small maxima between 40 and $45 \mathrm{~km}$ and almost constant values above approximately $52 \mathrm{~km}$.

These changes in potential energy with height for each of the June nights are also apparent in the mean vertical wavenumber power spectra derived for the height ranges $35-50 \mathrm{~km}$ and 50-65 km, represented by full and broken lines, respectively, in Fig. $6 \mathrm{a}-\mathrm{d}$. These spectra were derived from the individual 20 -min perturbation profiles for each night. The spectrum for each profile was obtained by first multiplying the values by $g$ / $N(z)$, linearly detrending the resulting profile, applying a Hanning window and carrying out a Fourier transform procedure. The mean of the individual spectra provided the spectrum for each night, the mean power for vertical wavelengths below $2 \mathrm{~km}$ being taken as the noise floor and subtracted from the mean spectral densities over the full spectral range. The uncertainties in the spectra are indicated by the vertical bars representing plus and minus one standard deviation about the mean values. It is seen that the power spectral densities in the lower height range on the two active nights, 27 and 28 June, are larger at vertical wavelengths greater than $5 \mathrm{~km}$ than those on the quiet nights, 26 and 29 June, and this is consistent with the corresponding differences between the profiles of potential energy in Fig. 5a, b. The quiet nights themselves show significant increases in this wavelength range between the lower and upper height ranges, this probably accounting for the corresponding changes in potential energy apparent in Fig. 5a. On the two active nights there is a general similarity between the spectra for the two height ranges, especially on 27 June, and this is in keeping with the small overall height dependence of mean values shown in Fig. 5b.

The large vertical wavenumber tail, which characterises the vertical wavenumber power spectrum induced by gravity waves in the middle atmosphere, is represented by:

$F(m)=\frac{A N^{2}}{m^{3}}$,

where $F(m)$ is the power spectral density as a function of the vertical wavenumber and $A$ is a dimensionless number. The apparent constancy of $A$ with changes in height shown by Allen and Vincent (1995) and Whiteway and Casswell $(1994,1995)$ is considered to represent a 'saturation' of the tail spectrum, an upper limit on the spectral intensity being reached. However, the nature of the saturation process is the subject of some controversy (Dewan and Good, 1986; Smith et al., 1987; Weinstock, 1990; Hines, 1991)

The dot-dash lines in Fig. 6a-d represent for the June 1995 nights the saturation power spectral densities, $\frac{N^{2}}{10 m^{3}}$, which was derived from the Fritts (1989) result for density perturbations, based on the analysis of Smith et al. (1987). For each night, the heavy and light dotdashed lines refer to the lower and upper height ranges,

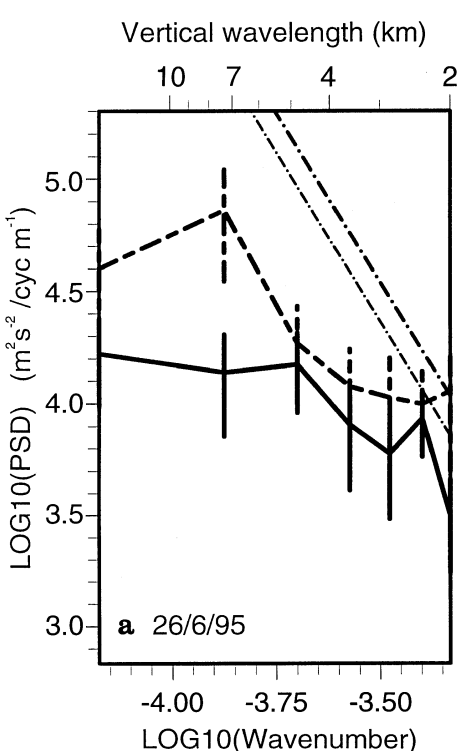

(cyc $\mathrm{m}^{-1}$ )

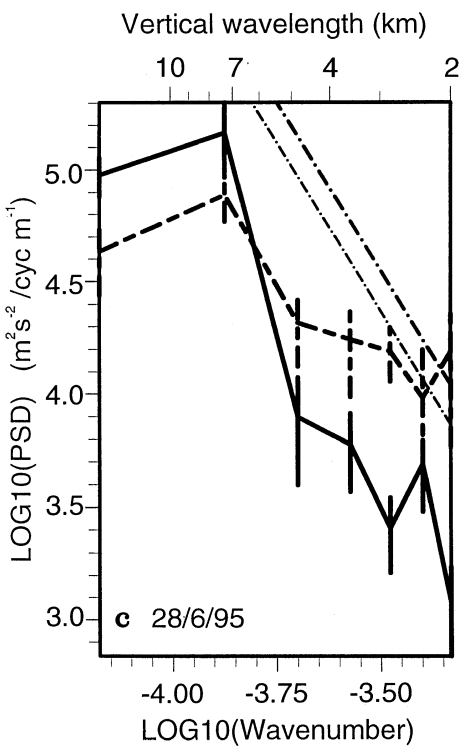

(cyc $\mathrm{m}^{-1}$ )
Vertical wavelength $(\mathrm{km})$

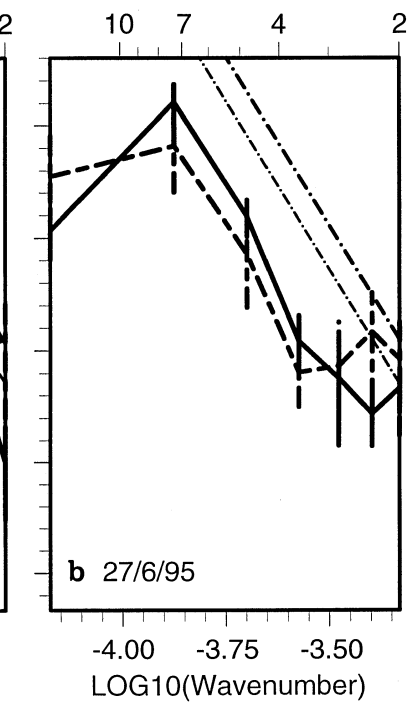

(cyc $\mathrm{m}^{-1}$ )

Vertical wavelength $(\mathrm{km})$

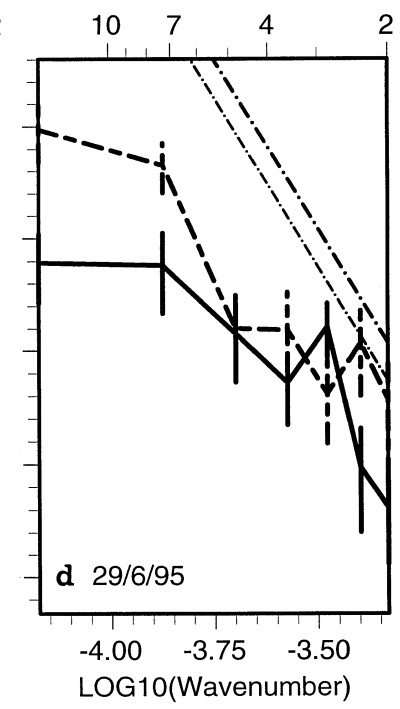

$\left(\right.$ cyc $\mathrm{m}^{-1}$ )
Fig. 6a-d. The mean vertical wavenumber power spectra for 35 $50 \mathrm{~km}$ and $50-65 \mathrm{~km}$, represented by full and broken lines, respectively, derived from observations on the nights of a 26, b 27, c 28 and d 29 June 1995, the vertical bars representing one standard deviation either side of the mean values. The dot-dash lines represent the saturation power spectral densities, $\frac{N^{2}}{10 \mathrm{~m}^{3}}$, the heavy and light lines referring to the $35-50-\mathrm{km}$ and $50-65-\mathrm{km}$, height ranges, respectively 
respectively, their relative positions reflecting the corresponding values of $N$ derived from the nightly mean temperature profiles obtained from the lidar measurements. On all these June nights, the observed power spectral densities are substantially below the saturation values except for short wavelengths in the upper height range. However, the general forms of the spectra are suggestive of that expected for saturation (Smith et al., 1987) with the log-log slope of both spectra on 27 June for wavelengths shorter than $7 \mathrm{~km}$ being close to the saturation value of -3 (Fig. 6b).

The profiles of potential energy per unit mass for the four February nights shown in Fig. 5c and d display larger magnitudes than those on the summer nights. Substantial differences are also observed between the two quiet nights, 13 and 19 February (Fig. 5c), and the pair of active nights, 22 and 24 February (Fig. 5d). Figure $5 \mathrm{c}$ shows growths with height on the 13 and 19 February by factors of about 2.5 between 35 and $50 \mathrm{~km}$, and little overall change at greater heights. The corresponding vertical wavenumber power spectra in Fig. 7a and $\mathrm{b}$ confirm these relatively small overall changes between $35-50-\mathrm{km}$ and $50-60-\mathrm{km}$ height ranges. In addition, the spectra for the upper height range show good agreement with the saturation limit values for wavelengths up to $5 \mathrm{~km}$. In contrast, the profiles of potential energy per unit mass for 22 and 24 February (Fig. 5d), show an overall growth by a factor of about 8 between 40 and $60-\mathrm{km}$. The corresponding vertical wavenumber spectra indicate that the growth in potential energy between height ranges $35-50 \mathrm{~km}$ and 50 $65 \mathrm{~km}$ extends over the whole range of wavelengths on 24 February (Fig. 7d) and over wavelengths longer than about $4 \mathrm{~km}$ on 22 February (Fig. 7c). As on all other nights, the saturation values for the lower height range slightly exceed those for the upper height range, because of the smaller $N$ values. It is seen that for these two February nights, the spectral densities for the lower height range are less than the corresponding saturation values and those for the upper height range are greater than the appropriate saturation values, for most wavelengths.

\section{Discussion}

In attempting to explain the different characteristics and intensities of density perturbations in the $35-65-\mathrm{km}$ height range on different nights (Figs. 3 and 4), it was of interest to examine VHF radar data for changes at lower heights which might correspond to differences in wave sources. For instance, it was found that the vertical wavenumber spectra of the horizontal velocity at heights of 10.5-18.5 km as observed with the MST radar system on the nights of 26, 27, and 28 June 1995 show increases with increased wavelength up to a value of $2 \mathrm{~km}$ and fairly constant values at larger wavelengths; no radar data was available for the night of 29 June. In particular, no growth in power spectral density was apparent in the radar-based spectra at wavelengths larger than $2 \mathrm{~km}$ on the nights of 27 and 28 June, which were characterised by pronounced density perturbations at wavelengths near 8 $\mathrm{km}$ in the height range $35-50 \mathrm{~km}$ (Fig. 3). However, these latter features are associated with waves of apparent periods of 6.4 and $9 \mathrm{~h}$, respectively, and the perturbations at lower- and middle-stratospheric heights might be expected to be separated by substantial distances horizontally if these values indicate corresponding large intrinsic periods. In view of the longer apparent periods deduced for the winter nights, the horizontal separation could be still larger.

No such large horizontal separation would be expected between these two height regions for waves

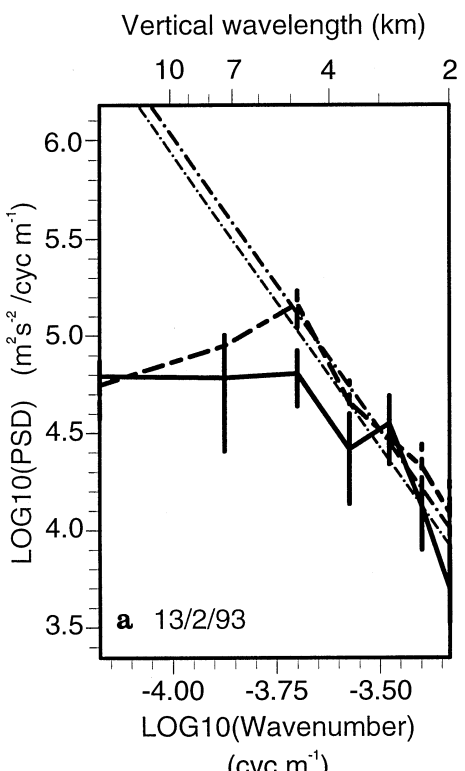

(cyc $\mathrm{m}^{-1}$ )

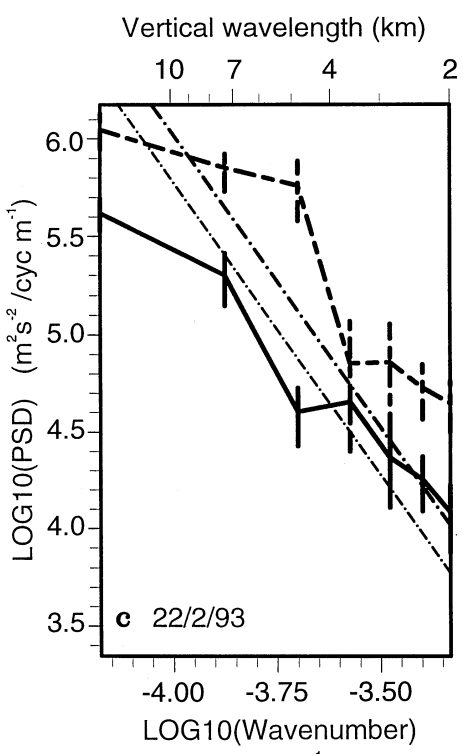

(cyc $\mathrm{m}^{-1}$ )
Vertical wavelength $(\mathrm{km})$

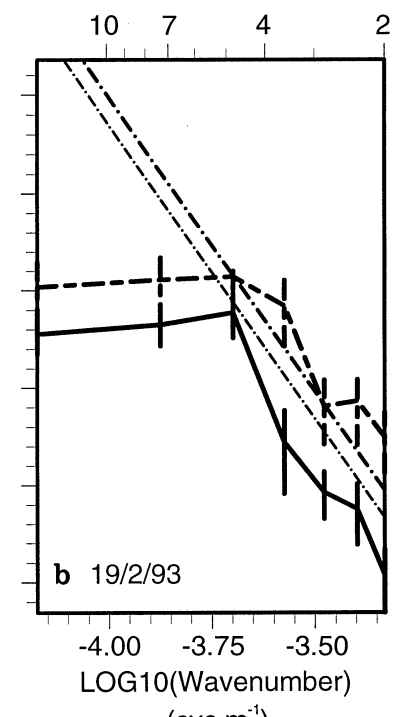

(cyc $\mathrm{m}^{-1}$ )
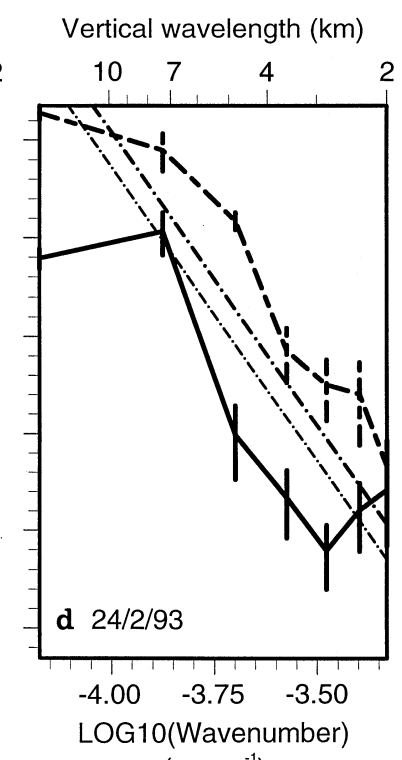

$\left(\right.$ cyc $\left.\mathrm{m}^{-1}\right)$
Fig. 7a-d. The mean vertical wavenumber power spectra for 35$50 \mathrm{~km}$ and $50-65 \mathrm{~km}$, represented by full and broken lines, respectively, derived from observations on the nights of a 13, b 19, $\mathbf{c} 22$ and d 24 February 1993, the vertical bars representing one standard deviation either side of the mean values. The dot-dash lines represent the saturation power spectral densities, $\frac{N^{2}}{10 m^{3}}$, the heavy and light lines referring to the $35-50-\mathrm{km}$ and $50-65-\mathrm{km}$ height ranges, respectively 
associated with orographic sources. Radar observations of oscillations in vertical velocities, which have been taken as an indication of mountain wave activity at Aberystwyth (Prichard et al., 1995), show large wavelength features extending up to $20 \mathrm{~km}$ on 19 and 22 February 1993 (Fig. 8a), whereas the corresponding weaker and shorter wavelength disturbances on 13 February are confined to heights below $8 \mathrm{~km}$ (Fig. 8b); no such wave activity was seen on 24 February, or on the three summer nights 26-28 June 1995 for which radar data were available. The density perturbations at heights above $35 \mathrm{~km}$ on the two pairs of nights 13 and 19 February (Fig. 4a, b) and 22 and 24 February (Fig. 4c, d), have been shown to be similar, but the two pairs were quite different. Similar differences between the two pairs can also be observed in the profiles of the potential energy per unit mass (Fig. 5c, d) and the vertical wavenumber power spectra (Fig. 7a, b, and c, d). This, together with Fig. 8, implies that the mountain wave activity on 19 and 22 February may have been removed at heights between 20 and $35 \mathrm{~km}$. The radar measurements of wind are confined to the height range 2-20 km, and for a more extended height coverage reference has been made to the radiosonde measurements at Valentia $\left(51.9^{\circ} \mathrm{N}, 10.2^{\circ} \mathrm{W}\right)$. This data shows that on 19 February the wind vector rotated anticlockwise continuously from $\mathrm{N} 350^{\circ} \mathrm{E}$ near the surface to $\mathrm{N} 265^{\circ} \mathrm{E}$ at $30 \mathrm{hPa}(\approx 24 \mathrm{~km})$. This near-orthogonal rotation implies that the component of wind in the direction of the mountain wave would be zero at the greater height, corresponding to the presence of a critical level and hence severe wave absorption (Worthington and Thomas, 1996). Similarly, for 22 February, the wind vector shows a continuous anticlockwise rotation with increasing height from a direction of $\mathrm{N} 340^{\circ} \mathrm{E}$ near the surface to $\mathrm{N} 278^{\circ} \mathrm{E}$ at the highest level of $20 \mathrm{hPa}(\approx 27 \mathrm{~km})$. If this rotation with height continued, an orthogonal condition leading to criticallayer absorption could again occur at a height below the
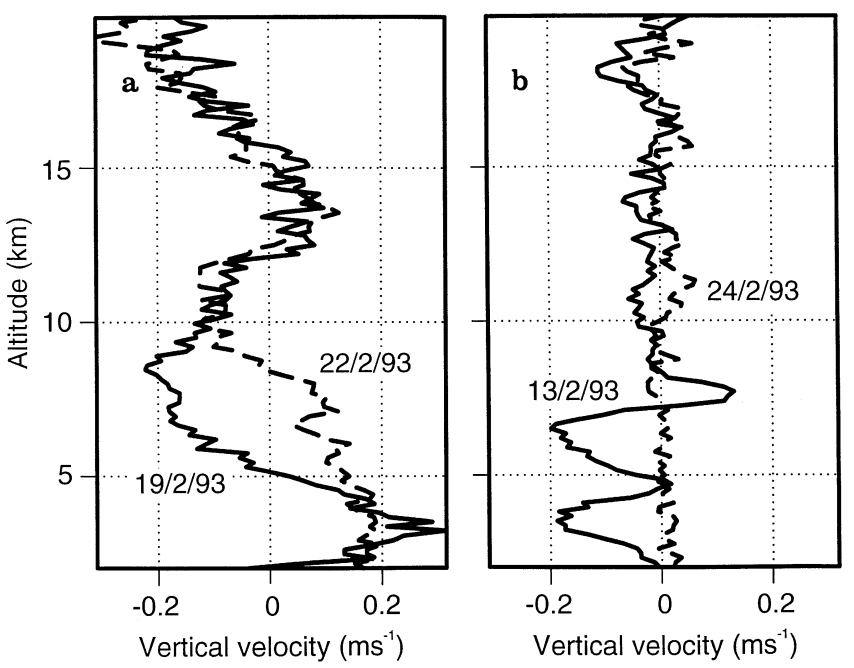

Fig. 8a, b. The mean vertical velocity profiles derived from MST radar measurements on a nights of 19 and 22 February 1993 and b nights of 13 and 24 February 1993 lower limit of the lidar observations. Thus, the apparent absence of effects due to mountain waves in the wave fields in the upper stratosphere and lower mesosphere on 19 and 22 February was very likely to be associated with critical-layer filtering. This suggests that the differences between the two pairs of nights in winter are associated with changes either in the vertical propagation or in the sources of long-period waves. Unfortunately, the large horizontal separation between the long-period waves observed in the upper stratosphere and their associated sources, together with the absence of wind information over heights up to $35 \mathrm{~km}$, prevents the identification of night-to-night changes arising from differences in sources or critical-layer effects.

A striking feature of the vertical wavenumber power spectra curves (Figs. 6 and 7) are the increases by a factor of about 3 shown between height intervals 35$50 \mathrm{~km}$ and $50-65 \mathrm{~km}$ at all wavelengths on 24 February (Fig. 7d) and at wavelengths longer than $4 \mathrm{~km}$ on 22 February (Fig. 7c); the results for 19 February (Fig. 7b) show a similar sense of change but of smaller magnitude. Similar increases in power spectral density, over the whole vertical wavelength range, between the upper stratosphere and lower mesosphere have been reported by Shibata et al. (1988), who found a change by a factor of 2 to 3 in the mean power spectral density for a total of 13 profiles, and by Wilson et al. (1991a, b), who found increases by factors of 2 to 5 for individual nights and by factors of 3 to 10 for monthly means; between the stratosphere and mesopause region, Beatty et al. (1992) and Senft et al. (1993) reported still larger increases, corresponding to factors of about 10 at a wavelength of $4 \mathrm{~km}$.

The growth by a factor of 3 observed between the two height ranges on the two active heights, 22 and 24 February (Fig. 7c, d), cannot be explained by changes in $N^{2}$ between these two ranges (Eq. 2). As shown by the lines representing the saturation levels, these amount to factors less than unity, namely 0.57 and 0.67 , respectively. As mentioned in Sect. 3, the individual temperature profiles during these nights show that temperature gradients approaching the dry adiabatic lapse rate are largely confined to heights near $50 \mathrm{~km}$ and above (Fig. 2a, b), i.e. convective instabilities seem to occur in the upper of the two height ranges for which vertical wavenumber spectra are shown (Fig. 7c, d). It is possible that on the basis of saturation caused by linear instabilities (Smith et al., 1987), these convective instabilities would be generated by waves of intrinsic periods much shorter than the inertial period at Aberystwyth $(\approx 15.1 \mathrm{~h})$, whereas waves of periods near such a value could satisfy the small amplitude thresholds for dynamic instabilities in the lower height range $35-50 \mathrm{~km}$ (Fritts and Rastogi, 1985). A similar suggestion has been made by Wilson et al. (1991a, b). An alternative explanation of the differences between the vertical wavenumber power spectra at the two altitudes in Fig. 7c, d can be invoked in terms of the Doppler spreading mechanism (Hines, 1991). Hines (1993) has shown that differences in the saturated part of the spectra can arise from changes in $A$ attributed to the form of the source spectrum. It is of 
interest to note that the vertical wavenumber power spectra of the horizontal velocity for the troposphere and lower stratosphere on 22 and 24 February show similar forms to those for the upper stratosphere and lower mesosphere (Fig. 7c, d), except that the changes of slope occur at small vertical wavelengths, near $3 \mathrm{~km}$. Attention has already been drawn to the possible large horizontal separation between sources and the perturbations observed in the upper stratosphere and lower mesosphere. However, if these spectra at lower heights are representative of the source, the analysis of Hines (1993) would suggest that the value of $A$ would be height independent, in contrast to the results in Fig. $7 \mathrm{c}$, d.

The corresponding vertical wavenumber power spectra for the quiet night on 13 February (Fig. 7a) show little change between the $35-50-\mathrm{km}$ and $50-65-\mathrm{km}$ height ranges, whereas those for the quiet night on 19 February (Fig. 7b) show some growth in power spectral densities, especially at vertical wavelengths less than $4.5 \mathrm{~km}$. It is perhaps surprising that for each of these nights no marked change with height is shown at longer wavelengths for which the approximate zero log-log slope implies the absence of saturation effects.

As noted in Sect. 3, the power spectral densities for both height ranges on the June 1995 nights are well below the corresponding saturation levels (Fig. 6). Furthermore, the individual temperature profiles for those nights have shown little evidence of convective instabilities. However, the active nights -27 and 28 June - show relatively little or no growth with height (Figs. 5b and $6 \mathrm{~b}, \mathrm{c}$ ), and even for the quiet nights such growth seems to be restricted to vertical wavelengths greater than $5 \mathrm{~km}$ (Fig. 6a, d).

\section{Conclusions}

Studies of the characteristics of gravity waves in the 35$65 \mathrm{~km}$ height range on four successive or closely spaced nights in June 1995 and February 1993 are carried out using Rayleigh lidar measurements at Aberystwyth, supplemented by wind measurements at lower heights using a co-located VHF radar system and radiosondes from Valentia. In each period, two pairs of nights are identified between which the wave activity shows marked differences.

The radar vertical velocity data show the presence of mountain waves up to $20 \mathrm{~km}$ on two of the winter nights, but the radiosonde wind data indicate their removal by critical-layer absorption between 20 and $35 \mathrm{~km}$, so that they do not contribute to the night-tonight differences observed by the lidar data in the 35-65$\mathrm{km}$ height range. Instead, such differences in both the June and February periods seem to be associated with the presence or absence of long-period waves with vertical wavelengths near 8 and $10 \mathrm{~km}$, respectively.

For the June nights, the vertical wavelength power spectra show spectral densities well below the saturation levels, except at the smallest wavelengths. On one of the two nights showing $8-\mathrm{km}$ vertical wavelength waves below $50-\mathrm{km}$, the power spectra for $30-50-\mathrm{km}$ and $50-$ $65-\mathrm{km}$ height ranges are very similar and show the log$\log$ slope of -3 characteristic of saturation. For the two nights in February showing no evidence of $10-\mathrm{km}$ vertical wavelength waves, relatively little change with height is shown in the total potential per unit mass or in the vertical wavelength spectral for the two height ranges. However, the power spectral densities for the upper height range on both nights show good agreement with the saturation values for vertical wavelengths up to $5-\mathrm{km}$. For the two February nights showing the presence of $10-\mathrm{km}$ vertical wavelength waves, the vertical wavenumber spectra show substantial differences in spectral densities between the two height ranges, over the full spectral range for one night and for wavelengths longer than $4-\mathrm{km}$ on the other. These differences and the poor agreement with the saturation values seem to be inconsistent with a linear saturation process.

Acknowledgements. The authors are grateful to Liam Keegan of the Irish Meteorological Office for his help in obtaining wind measurements from Valentia.

Topical Editor F. Vial thanks T.E. Van Zandt and R. Wilson for their help in evaluating this paper.

\section{References}

Allen, S. J., and R. A. Vincent, Gravity wave activity in the lower atmosphere: seasonal and latitudinal variations, J. Geophys. Res., 100, 1327-1350, 1995.

Beatty, T. J., C. A. Hostetler, and C. S. Gardner, Lidar observations of gravity waves and their spectra near the mesopause and stratopause at Arecibo, J. Atmos. Sci., 49, 477-496, 1992.

Booker, J. R., and F. P. Bretherton, The critical layer for internal gravity waves in a shear flow, J. Fluid. Mech., 27, 513-539, 1967.

Bretherton, J. R., The propagation of groups of internal gravity waves in a shear flow, Q.J.R. Meteorol. Soc., 92, 466-480, 1966.

CIRA-1986, Cospar international reference atmosphere: 1986. Part II: middle atmosphere models, Adv. Space. Res., 10, No 12, 357-517, 1990.

Dewan, E. M., and R. E. Good, Saturation and the universal spectrum for vertical profiles of horizontal scalar winds in the atmosphere, J. Geophys. Res., 91, 2742-2748, 1986.

Fritts, D. C., A review of gravity wave saturation processes, effects, and variability in the middle atmosphere, Pageoph. 130, 343371, 1989

Fritts, D. C., and K. Rastogi, Convective and dynamical instabilities due to gravity wave motions in the lower and middle atmosphere: theory and observations, Radio Sci., 20, 12471277, 1985.

Hines, C. O., The saturation of gravity-waves in the middle atmosphere. 2. Development of Doppler-spread theory, $J$. Atmos. Sci., 48, 1360-1379, 1991.

Hines, C. O., Pseudo-saturation of gravity waves in the middle atmosphere: an interpretation of certain lidar observations, J.Atmos. Terr. Phys., 55, 441-445, 1993.

Hodges, R. R., Generation of turbulence in the upper atmosphere by internal gravity waves, J. Geophys. Res., 72, 3455-3458, 1967.

Hodges, R. R., Eddy diffusion coefficients due to instabilities in internal gravity waves, J. Geophys. Res., 74, 4087-4090, 1969.

Holton, J. R., The influence of gravity wave breaking on the general circulation of the middle atmosphere, J. Atmos. Sci., 40, 2497-2507, 1983.

Houghton, J. T., The stratosphere and the mesosphere, $Q . J$. $R$. Meteorol. Soc., 104, 1-29, 1978. 
Jenkins, D. B., D. P. Wareing, L. Thomas, and G. Vaughan, Upper stratospheric and mesospheric temperatures derived from lidar observations at Aberystwyth, J. Atmos. Terr. Phys., 49, 287$298,1987$.

Lindzen, R. S., Turbulence and stress owing to gravity-wave and tidal breakdown, J. Geophys. Res., 86, 9707-9714, 1981.

Marsh, A. K. P., N. J. Mitchell, and L. Thomas, Lidar studies of stratospheric gravity-wave spectra, Planet. Space Sci., 39, 15411548, 1991.

Mitchell, N. J., L. Thomas, and A. K. P. Marsh, Lidar observations of long-period gravity waves in the stratosphere, Ann. Geophysicae, 9, 588-596, 1991.

Naujokat, B., K. Petzoldt, R. Lenschow, M. Wiesner, and R. C. Wohlfart, The stratospheric winter 1992/1993: a cold winter with a minor warming and a late final warming, Beil. Berliner Wetterkarte, SO 21/93, 1993.

Prichard, I. T., L. Thomas, and R. M. Worthington, The characteristics of mountain waves observed by radar near the west coast of Wales, Ann. Geophysicae, 13, 757-767, 1995.

Senft, D. C., C. A. Hostetler, and C. S. Gardner, Characteristics of gravity wave activity and spectra in the upper stratosphere and upper mesosphere at Arecibo during early April 1989, J. Atmos. Terr. Phys., 55, 425-439, 1993.

Shibata, T., S. Ichimori, T. Narikiyo, and M. Maeda, Spectral analysis of vertical temperature profiles observed by lidar in the upper stratosphere and lower mesosphere, J. Meteorol. Soc. Jpn., 66, 1001-1005, 1988.

Sica, R. J., and M. D. Thorsley, Measurements of superadiabatic lapse rates in the middle atmosphere, Geophys. Res. Lett., 20, 2797-2800, 1996.
Smith, S. A., D. C. Fritts, and T. E. VanZandt, Evidence for a saturated spectrum of atmospheric gravity-waves, J. Atmos. Sci., 44, 1404-1410, 1987.

Thomas, L., D. B. Jenkins, D. P. Wareing, and M. Farrington, Laser-radar observations in mid-Wales of aerosols from the ElChichon eruption, Nature, 304, 248-250, 1983.

VanZandt, T. E., A universal spectrum of buoyancy waves in the atmosphere, Geophys. Res. Lett., 9, 575-578, 1982.

Weinstock, J., Saturated and unsaturated spectra of gravity waves, and scale-dependent diffusion, J. Atmos. Sci., 47, 2211-2225, 1990.

Whiteway, J. A., and A. I. Carswell, Rayleigh lidar observations of thermal structure and gravity wave activity in the high Arctic during a stratospheric warming, J. Atmos. Sci., 51, 3122-3136, 1994.

Whiteway, J. A., and A. I. Carswell, Lidar observations of gravitywave activity in the upper-stratosphere over Toronto, $J$. Geophys. Res., 100, 14113-14124, 1995.

Wilson, R., M. L. Chanin, and A. Hauchecorne, Gravity waves in the middle atmosphere observed by Rayleigh lidar. 1. Casestudies, J. Geophys. Res., 96, 5153-5167, 1991a.

Wilson, R., M. L. Chanin, and A. Hauchecorne, Gravity-waves in the middle atmosphere observed by Rayleigh lidar. 2. Climatology, J. Geophys. Res., 96, 5169-5183, 1991 b.

Worthington, R. M. and L. Thomas, Radar measurements of critical-layer absorption in mountain waves, Q.J.R. Meterol. Soc., 122, 1263-1282, 1996. 